\title{
JUAN DE BEAUMONT, PRIOR DEL HOSPITAL: PROMOCIÓN AL CARGO Y CONTROL DE LA ORDEN POR PARTE DE UNA FACCIÓN NOBILIARIA EN NAVARRA (1433-1451)
}

Julia Pavón Benito*

Universidad de Navarra

\begin{abstract}
Resumen
Este artículo analiza el momento y el contexto que dio lugar a la toma de posesión del cargo de prior del Hospital de San Juan de Jerusalén por parte de Juan de Beaumont en 1435, y las primeras actuaciones de su gobierno en dicha institución hasta el inicio de la guerra civil navarra en 1451. La documentación sanjuanista (AHN y National Library of Malta), complementada por la información de los fondos del reino custodiados en el Archivo General de Navarra, revela un intenso período de cambios en la orden a partir de 1433 y durante los tres lustros siguientes. Ello invita a pensar, teniendo en cuenta la compleja situación peninsular y navarra del primer tercio del siglo XV, en el interés que manifestó una de las facciones nobiliarias del reino de Navarra, la de los Beaumont, por controlar la dirección y organización del priorato sanjuanista.
\end{abstract}

\section{Palabras clave}

Priorato de San Juan de Jerusalén en Navarra. Juan de Beaumont. Facciones nobiliarias en la Navarra medieval.

\begin{abstract}
This paper analyses the circumstances that led John of Beaumont to take office as prior of the Hospitaller order of St John of Jerusalem in Navarre in 1435, as well as his first actions undertaken as governor of the priory, until the outbreak of the Navarrese civil war in 1451. The Hospitaller documentation, guarded in the National Historical Archive of Madrid and in the National Library of Malta, complemented by relevant information from collections of the General Archive of Navarre, reveal that a period of intense changes in the guidelines of the Hospitaller order took place throughout these fifteen years. Considering the political context of the first three decades of the fifteenth century, not only in Navarre but also in the rest of the Peninsula, it is of interest to focus on the effort made by one of the noble factions of the Kingdom of Navarre, namely the Beaumonts, to control the management and the organization of the priory of St John.
\end{abstract}

\section{Keywords}

Priory of Saint John of Jerusalem in Navarre. Juan de Beaumont. Noble Factions in Medieval Navarre.

\section{Résumé}

Cet article analyse le moment et le contexte qui donnèrent lieu à la prise de possession de la charge de prieur de l'Hôpital de Saint-Jean-de-Jérusalem par Jean de Beaumont en 1435, et les mesures

\footnotetext{
Email: jpavon@unav.es
} 
prises par lui à la tête de cette institution, jusqu'au début de la guerre civile navarraise en 1451. La documentation de l'Ordre de Saint-Jean (AHN et National Library of Malta), complétée par les fonds du royaume conservés aux Archives Générales de Navarre, révèle une période intense de changements dans l'ordre à partir de 1433 et durant les trois lustres qui suivent. Ce qui témoigne, si l'on tient compte de la situation complexe dans la Péninsule et en Navarre durant le premier tiers du XVe siècle, de l'intérêt manifesté par une des factions nobiliaires du royaume de Navarre, celle des Beaumont, pour le contrôle de la direction et de l'organisation du prieuré de Saint-Jean.

\section{Mots clés}

Prieuré de Saint-Jean-de-Jérusalem en Navarre. Jean de Beaumont. Factions nobiliaires de la Navarre médiévale.

El año 1435 accedió al cargo de prior de San Juan de Jerusalén en Navarra Juan de Beaumont, y desde ese momento hasta su muerte, acaecida en 1487 dirigió esta circunscripción hospitalaria, dentro de un complejo panorama político en el reino de Navarra, en la Península Ibérica y, por extenso, en el ámbito europeo-occidental y mediterráneo. El dilatado arco cronológico de su gobierno tuvo unos inicios marcados por una provisión prioral anómala, que obedeció probablemente al interés de su linaje por controlar esta dignidad institucional, con una significativa base patrimonial y una especial proyección no sólo peninsular, sino internacional. De hecho, las primeras noticias documentales relativas a su sucesión del anterior prior, Martín Martínez de Olloqui, hacia 1433-1435, así como a su posterior investidura de 1441, parecen expresar el despliegue de ciertas maniobras familiares con la finalidad a situarle a la cabeza de la orden, frente al más idóneo de los candidatos y con mejor trayectoria de entre las filas de los caballeros sanjuanistas navarros: Sancho de Echauz.

Alcanzar la dirección del Hospital, tanto en este priorato como en otros, fue uno de los objetivos de algunas oligarquías bajomedievales que buscaban la promoción y el prestigio social y económico, o la cercanía a los círculos de poder, como se ha estudiado, por ejemplo, en Castilla, Cataluña y la Castellanía de Amposta. Pero en este caso, el interés de Juan de Beaumont por dirigir el Hospital ante la oposición de Sancho de Echauz; o lo que es lo mismo, el conflicto que se divisa entre los Beaumont y los Echauz, facciones nobiliarias opuestas, por hacerse con el cargo, entre 1433 y 1441, revela que también el proceso de banderización de los grupos aristocráticos, analizado con cierto detalle por la historiografía en Navarra, extendió su radio de acción sobre los cuadros de vida de esta organización hospitalario-militar.

A la vista de estas circunstancias, este artículo pretende estudiar el momento y contexto que dio lugar a la toma de posesión de la dirección de San Juan por parte de Juan de Beaumont, así como de los tres primeros lustros de su gobierno que abarcan hasta el inicio de la guerra civil navarra en 1451, y que cierran una primera etapa a la cabeza de esta entidad. Este trabajo, por tanto, se centrará en indagar sobre los motivos y circunstancias de su ascenso al priorato, en 1435, para pasar en un segundo término a trazar las líneas maestras de sus pautas gubernativas, principalmente orientadas al control de 
encomiendas, bajo caballeros de su confianza y partido nobiliario; y de sus actividades dirigidas a la gestión y administración de las rentas del Hospital. Además, esta primera andadura de Juan al frente de este organismo servirá para plantear en un futuro el estado y desarrollo de la orden al iniciarse el conflicto civil en Navarra en 1451. Qué duda cabe que el papel de los hospitalarios durante la guerra merecería un capítulo aparte ${ }^{1}$, así como lo que acontece a partir de la muerte del príncipe de Viana en Barcelona (1461, septiembre 23), antesala de otro enfrentamiento civil, esta vez en Cataluña (1462-1472), escenario en el que también actuó el prior navarro. La presencia y el protagonismo de Juan de Beaumont en ambas lides, como deja entrever la documentación, reflejan una proyección en el tiempo y en el espacio de sus intereses políticos familiares y también, en cierta forma, la instrumentalización de su dignidad de caballero y del prestigio y los recursos sanjuanistas ${ }^{2}$. No obstante, y en esta investigación, dichas etapas quedarán fuera del presente objeto de análisis, con el ánimo de ser analizadas en próximas ocasiones.

En otro orden de cosas, y en el plano metodológico, procede mencionar, dentro de estas primeras líneas introductorias, que para realizar este artículo se han consultado y examinado los fondos documentales conservados en el Archivo Histórico Nacional de Madrid (Sección Órdenes Militares) y en el Archivo Real y General de Navarra en Pamplona (Sección de Comptos y Sección de Clero, Convento de sanjuanistas de Puente la Reina), depósitos archivísticos peninsulares donde se halla una parte significativa de los textos referidos al gobierno de priorato sanjuanista navarro, y a los círculos de poder y linajes nobiliarios de esta demarcación hispánica. Del mismo modo, se han incluido y considerado las referencias recogidas en los registros o Libri bullarum de la National Library of Malta (Sección 5), centro archivístico de referencia de la orden, en la Valletta.

En última instancia, ha de considerarse que el priorato navarro del Hospital ha sido ya objeto de atención investigadora dentro de estas coordenadas temporales de la decimoquinta centuria, si bien bajo un prisma institucional a partir de los trabajos de Carlos Barquero Goñi ${ }^{3}$; o en un marco centrado en los modelos y características funcionales

\footnotetext{
Se han realizado un primer acercamiento a esta cuestión en Julia PAvón BENITo, "The Prior of the Knights Hospitaller in the Navarrese Civil Conflict (1451-1461)", Society for the Study of the Crusades and the Latin East Conference, Cáceres (June 25th - 29th, 2012), Universidad de Extremadura (en prensa).

2 Recoge la implicación del prior en la guerra catalana Pierre Bonneaud, Els Hospitalers catalans a la $f i$ de l'Edat Mitjana. L'orde de l'Hospial a Catalunya i a la Mediterrànea, 1396-1472, Pagès editors, Lleida, 2008 , pp. 364-365 y pp. 372-375. Del mismo autor y para contextualizar la trayectoria del priorato de Cataluña: Le prieuré de Catalogne, le conuvent de Rhodes et la couronne d'Aragon 1415-1447, Études \& Communication Editions, Bez-et-Esparon, 2004.

3 Santos García Larragueta, focalizó su obra principal en los siglos XII y XIII: El Gran Priorado de Navarra de la Orden de San Juan de Jerusalén (siglos XII-XIII), Institución Príncipe de Viana, Pamplona, 1957, 2 vols; aunque también publicó un artículo centrado en el siglo XIV: "La orden de San Juan de Jerusalén en Navarra. Siglo XIV", Las Órdenes Militares en el Mediterráneo Occidental. Siglos XIII-XVIII: coloquio celebrado los días 4, 5 y 6 de mayo de 1983, Casa de Velázquez-Instituto de Estudios Manchegos, MadridCiudad Real, 1989, pp. 103-138. De especial valía es el trabajo de Consuelo Gutiérrez del Arroyo, Catálogo de la documentación Navarra de la orden de San Juan de Jerusalén en el Archivo Histórico Nacional (siglos XII-XIX), Pamplona, Gobierno de Navarra, 1992, 2 vols., un instrumento imprescindible para el acceso a los fondos del priorato navarro en el mencionado archivo (se citará CSJNa). También son importantes los estudios de Carlos BARQuero GoñI, "Las relaciones entre Rodas y los hospitalarios navarros durante el siglo XV (años
} 
de gobierno, tanto en el ámbito regional como conventual, por parte de María Bonet Donato $^{4}$. Empero, y a pesar de estos antecedentes, el presente trabajo amplía las perspectivas de estudio de este priorato hispano, valorando la realidad y tendencias, tanto sociales y políticas, del entramado navarro. De esta forma, y contrastando el cuadro y situación general del reino, se plantea observar la naturaleza y límites de la relación entre la orden y los grupos de poder, así como las consecuencias que ello supuso, dentro de las coordenadas de una etapa, la del segundo cuarto del siglo XV.

\section{El reino de Navarra: de los Evreux a los Trastámara}

Cuando Blanca de Evreux se convierte en reina de Navarra el ocho de septiembre de 1425, tras el fallecimiento de su padre, Carlos III el Noble (1387-1425), esta dinastía de origen francés llevaba ya tres generaciones en el trono de este solar soberano hispánico ${ }^{5}$. En el momento de asumir la soberanía, Blanca estaba casada con uno de los miembros de la casa real aragonesa, Juan de Trastámara, hijo de Fernando I de Antequera (1412-1416) y duque de Peñafiel, y hermano, por tanto, de Alfonso V el Magnánimo (1416-1458). Huelga detallar el prestigio político y peso económico de este linaje en la Península Ibérica, tanto a través de su patrimonio y movimientos partidistas alrededor de los centros de poder en el reino de Castilla, como por las actividades del gobierno regio en todos los territorios de la corona de Aragón a partir de $1412^{6}$.

1400-1480)", Medievalismo, 5 (1995), pp. 151-188; "Repercusiones de la defensa de Rodas en los Hospitalarios navarros a fines de la Edad Media (siglos XIV-XV)", El Mediterráneo: hechos de relevancia histórico-militar y sus repercusiones en España. V Jornadas Nacionales de Historia Militar, Universidad de Sevilla, Sevilla, 1997, pp. 199-217; "The Hospitallers and the kings of Navarre in the Fourteenth and Fifteeenth Centuries", The Military orders. Volume 2. Welfare and Warfare, Helen Nicholson (ed.), Aldershot Publisher-Brookfield, Ashgate, 1998, pp. 349-354; La orden de San Juan de Jerusalén en Navarra (siglos XIV-XV), Ed. Fuentes Dutor, Pamplona, 2004, y "Los hospitalarios y los últimos reyes de Navarra (1483-1512)", The Hospitallers, the Mediterranean and Europe. Festschrift for Anthony Luttrell, Karl Borchardt, Nikolas Jaspert y Helen J. Nicholson (eds.), Aldershot-Burlington, Ashgate, 2007, pp. 233-242.

4 María Bonet Donato, "La centralización en el gobierno de priorato de Navarra: el convento de Rodas y la gestión de las encomiendas", La orden del Hospital de San Juan de Jerusalén. Contextos y trayectorias del Priorato de Navarra medieval, Julia Pavón y María Bonet (eds.), CSIC-Eunsa, Madrid-Pamplona, 2013, pp. 179-271.

5 Sigue siendo imprescindible para situarnos en los más inmediatos antecedentes del reinado de Blanca, el estudio de las estrategias políticas y familiares diseñadas por su padre, y que se pueden seguir en la ya clásica monografía de José RAmón CASTRo, Carlos III el Noble, rey de Navarra, Institución Príncipe de Viana, Pamplona, 1967. Igual de importante es la lectura de las reflexiones de Eloísa Ramírez Vaquero, "La reina Blanca y Navarra", Príncipe de Viana, 60 (1999), pp. 323-340, que replantea las cuestiones básicas de este reinado en un amplio contexto temporal y espacial, abriendo así una nítida línea de investigación en todos los frentes de un tema sobre una figura hasta cierto punto mal conocida, pero, en buena medida, conocida (p. 323). Con un planteamiento historiográfico renovado, la misma autora ha publicado Carlos III, rey de Navarra: Príncipe de sangre Valois (1387-1425), Trea, Gijón, 2007, que proporciona también las claves para comprender lo que acontecerá durante el reinado de Blanca y el panorama político y social del reino navarro.

6 Jaume Vicens Vives, Juan II de Aragón (1398-1479): Monarquía y revolución en la España del siglo $X V$, Paul H. Freedman y Josep M. Muñoz (eds.), Urgoiti Editores, Pamplona, 2003 ( $1^{\mathrm{a}}$ ed. Barcelona, Teide, 
Trasciende a este artículo detenerse, en esta ocasión por tanto, sobre la intensa actividad diplomática y militar, así como el complejo panorama peninsular que rodeó la biografía del rey Juan de Navarra y más tarde de Aragón (1458), estudiados por Jaime Vicens Vives o Luis Suárez Fernández; y más recientemente revisados en distintos ejercicios de síntesis ${ }^{7}$.

Eloísa Ramírez Vaquero ${ }^{8}$, que ha establecido los parámetros de análisis más vigentes para el reinado de Blanca y de la etapa anterior y posterior al ejercicio de su potestas soberana, ha recuperado la integridad de su retrato y contexto político intentando poner de relieve la figura de la reina como algo más que un contrapunto, que también lo fue de su marido ${ }^{9}$. De la misma forma, ha desenmascarado las equivocadas e inexactas caretas atribuidas por la historiografía romántica a dicha época y reinado ${ }^{10}$, planteando y poniendo de relieve cuestiones ensombrecidas por el conflicto entre padre e hijo a partir de 1451. Entre otras cosas, la autora apunta a temas y factores hasta ahora soslayados y que requerirían un ejercicio amplio de contextualización y trabajo, tanto de fuentes como de temas, dentro del teatro de operaciones peninsular. Es el caso, por ejemplo, de la intensa actividad política de la soberana en Castilla hasta su muerte o también del valor y transcendencia de actuaciones de Juan de Trastámara en la corte navarra. En definitiva, pese a la imagen decimonónica del reinado y del conflicto, los problemas de la monarquía navarra, derivados de la trama de intereses castellanos -y por extenso aragoneses-, y que se detectan ya en los primeros años del matrimonio (1429-1430), cristalizaron en algo más que una mera pugna entre padre e hijo.

La entrada de Navarra en la órbita Trastámara, desde el enlace entre Blanca y Juan (1419-1420), y la temprana desaparición de la "reina propietaria", a partir de 1441, ni eclipsaron la supuesta "identidad" navarra, ni causaron la fijación partidista de la sociedad navarra, que detonó más tarde en el conflicto dinástico entre el heredero, Carlos, y su padre y tutor, Juan II; o lo que tradicionalmente se conoce como la guerra entre dos bandos antagónicos: los beaumonteses y fieles a la causa del príncipe, y los agramonteses o partidarios del rey ${ }^{11}$.

1953). Luis SuÁrez Fernández, “Los Trastámaras de Castilla y Aragón en el siglo XV (1407-1474)”, Historia de España, Ramón Menénez Pidal (dir.), vol. 15, Espasa-Calpe, Madrid, 1964, pp. 3-845.

7 Julio Valdeón Baruque, "Castilla en tiempos de doña Blanca", Príncipe de Viana, 60 (1999), pp. 25-34 y José Ángel Sesma MuÑoz, "La reina doña Blanca y Aragón”, Príncipe de Viana, 60 (1999), pp. 35-48.

8 Eloísa Ramírez Vaquero, Solidaridades nobiliarias y conflictos políticos en Navarra (1387-1464), Gobierno de Navarra, Pamplona, 1990.

9 Eloísa Ramírez Vaquero, "La reina Blanca y Navarra", p. 326.

10 Georges Desdevises du Dezert, Don Carlos de Aragón, príncipe de Viana. Estudio sobre la España del norte en el siglo $X V$, Pascual Tamburri (trad. y ed.), Gobierno de Navarra, Pamplona, 1999 y para la etapa posterior: Prosper Boissonnade, Histoire de la reunión de la Navarre a la Castille. Essai sur les relations des princes de Foix-Albret avec la France et l'Espagne (1479-1521), Alphonse Picard et Fils, Paris, 1893 (reed.: Historia de la incorporación de Navarra a Castilla: ensayo sobre las relaciones de los Príncipes de Foix-Albret con Francia y con España (1479-1521), E. Ramírez Vaquero (introducción y anotaciones); E. Ramírez Vaquero y Ana María Ramírez-Merz (trad.), Pamplona, Gobierno de Navarra, 2005).

11 Eloísa Ramírez Vaquero y Pascual Tamburri, El Príncipe de Viana, Gobierno de Navarra, Pamplona, 2001, pp. 36-50. 
La estirpe de los Beaumont, que a comienzos de la década de los años treinta no lideraba ninguna fuerza partidista contraria al castellano, sí que manifestó su interés por una institución como la de la orden de San Juan, con el objeto de controlar su radio de acción, no sólo regional sino también peninsular y vocacionalmente mediterráneo. Luis de Beaumont, y más tarde su hermano Juan, encabezaban una serie de partidos nobiliarios que venían manteniendo, desde tiempo atrás, un choque de intereses y un juego de fuerzas. La orden del Hospital también se convirtió en un espacio de fricción política dentro esta compleja trama social por su peso y su prestigio, no sólo dentro del reino sino más allá de sus propias fronteras.

\section{Promoción al cargo de Juan de Beaumont y primeros años de gobierno (1435- 1451)}

La larga etapa de gobierno prioral de Juan de Beaumont obliga, inicialmente, a fraccionar los distintos períodos de su gobierno atendiendo a las circunstancias políticas que ocurrieron en Navarra, y por extenso en la Península Ibérica. En este caso, el análisis propuesto para este artículo recoge la primera fase de desempeño de la función prioral hasta el momento del comienzo de la guerra civil navarra; esto es entre 1435 y 1451. Este período, por tanto, se inicia con un jovencísimo Juan -nacido el 3 de abril de 1419-, que alcanzó el cargo prioral en 1435; y termina con un activo freire y canciller (desde 1439), con una larga experiencia en el ejercicio de sus funciones como hospitalario, y también al servicio de la monarquía navarra.

$\mathrm{Su}$ linaje, estudiado y conocido, era de origen regio ${ }^{12}$. Tanto él, como su hermano mayor, Luis, el conde de Lerín, eran nietos de Luis de Beaumont, hermano a la sazón del rey Carlos II (1349-1387). Asimismo su estirpe, la de los Beaumont, se convirtió durante el siglo XV en uno de los linajes más activos e influyentes, en el plano político y patrimonial, tanto en Navarra como en la tierra de Soule y Labourd, por herencia materna y otras razones de gobierno ${ }^{13}$.

\subsection{El conflicto por la titularidad del priorato navarro con Sancho de Echauz (1433/35- 1441)}

La primera referencia documental de Juan, como prior de la orden de san Juan de Jerusalén, data de abril de $1435^{14}$; si bien no recibió formalmente la confirmación de

\footnotetext{
12 Jean DE JaURgain, "Les Beaumont-Navarre. Notes historiques et généalogiques", Revista Internacional de Estudios Vascos, 3 (1909), pp. 46-65.

13 Eloísa Ramírez Vaquero, Solidaridades nobiliarias, pp. 124-135.

14 Juan figura jurídica y documentalmente por primera vez en calidad de prior en el litigio para la provisión de los cargos eclesiásticos que se dirimió entre los vecinos de Esquíroz y Cordovilla (cuenca de Pamplona) y el Hospital, que se fecha el mes de abril de ese año (AHN, OO. MM., San Juan de Jerusalén, carp. 888, n. 291; CSJNa, n. 2733). Pocos meses después se le menciona como embajador de la reina Blanca ante la corte
} 
su dignidad prioral hasta el 19 de enero de $1441^{15}$. El fallecimiento o cese del prior anterior, Martín Martínez de Olloqui en 1433 o $1435^{16}$, pudo dar lugar a un conflicto por la dignidad prioral entre el linaje de los Beaumont y los Echauz. Son varias las cuestiones a tener en cuenta para valorar este último asunto: en primer lugar el inexplicable origen de la investidura hospitalaria de un joven de dieciséis años que no cumplía las condiciones estatutarias para acceder al cargo; en segundo término, y en el polo opuesto, la larga trayectoria en la orden de uno de los freires candidatos al puesto; y tercero, la existencia de un texto que recoge los ecos del litigio entre ambos personajes, Juan de Beaumont y Sancho de Echauz, ante la corte papal de Florencia ${ }^{17}$.

Sancho de Echauz, quizá uno de los más destacados miembros de la orden de San Juan en Navarra a comienzos del siglo XV, pudo entrar a disputar la máxima magistratura de esta demarcación hospitalaria con Beaumont, a tenor de su peso y prestigio dentro de este priorato y reino hispano. Su linaje, procedente de la Baja Navarra (Saint-Étiennede-Baïgorry) y descendiente del vizconde Jimeno García, prestó importantes servicios a los soberanos Carlos III y Juan II, desdoblándose en dos ramales, siendo los unos titulares de Baigorri y los otros señores de Arizmendi. Algunos miembros de su familia optaron por puestos de la administración, caso de Juan, su hermano de padre, que fue merino de Estella (1428-1450); plaza en la que le sucedió su hijo Carlos (1450-1458). Pero Sancho, dentro de los círculos reales y más tarde integrado en el hostal de la princesa de Viana (1441-1446) y señor de Arizmendi y de Osés (Ossès), por parte de madre, se hizo tempranamente un hueco dentro de las oligarquías de la institución

aragonesa, con el título de prior, en la documentación de Comptos (Florencio IDOATE, Archivo General de Navarra. Catálogo de la Sección de Comptos. Documentos, Aramburu, Pamplona, 1966, tomo 42, n. 299).

15 AHN, OO. MM., San Juan de Jerusalén, carp. 860, n. 35; CSJNa, n. 379.

16 En la actualidad y dentro del proyecto de investigación de la Universidad de Navarra ya mencionado, Anna K. Dulska realiza una tesis doctoral sobre el priorato navarro en tiempos de Martín Martínez de Olloqui (1383-1433/35). Su figura ya ha sido objeto de algunas publicaciones, como: "Del escudero de Esteríbar al caballero de Rodas. Comienzos de la carrera de Martín Martínez de Olloqui, futuro prior de la Orden de San Juan de Jerusalén en Navarra (s. XIV)", Príncipe de Viana, 262 (2015), pp. 443-456. No se ha podido precisar hasta el momento las circunstancias y la fecha de la muerte o cese en el cargo de Martín Martínez de Olloqui. Mientras que en los registros magistrales se documenta la provisión del cargo para Sancho de Echauz, el 5 de octubre de 1433 (NLM, 350, 159v.-160r.), el asiento aparece tachado, lo que supone que no se llevó a cabo; máxime cuando tres días después recibía la cámara magistral de Pedriz. Por otro lado, se conserva un texto fechado el 12 de febrero de 1435 en el que Martín Martínez de Olloqui preside un capítulo provincial (AHN, OO. MM., San Juan de Jerusalén, caja 8516, 13/2; CSJNa, n. 1686).

17 El Archivo Histórico Nacional de Madrid custodia el diploma de la respuesta de la cámara apostólica ante la apelación de Sancho de Echauz y en el que el auditor especial designado por el papa Eugenio IV, Antonio de San Vito, solicitaba la comparecencia de ambos hospitalarios en el plazo de 50 días (AHN, OO. MM., San Juan de Jerusalén, carp. 855, n. 87; CSJNa, n. 232). No se conservan otros testimonios relativos al caso o a la posible sentencia, por ejemplo, en los Registros Vaticanos (Eugenius IV, 1431-1447, Cittá del Vaticano: Archivio Segreto Vaticano, 1999, CDRom, II: ff. 13* + 355 (1440-1443), pero sería probablemente favorable al beaumontés, a tenor de los hechos posteriores. Antonio Altan o de San Vito fue embajador papal ante el concilio de Basilea y uno de los principales hombres de confianza del pontífice en los asuntos de gestión de la iglesia durante los primeros años de su pontificado (Joseph GiLl, Eugenio IV. Papa de la unión de los cristianos, Madrid: Espasa-Calpe, 1967, p. 91 y http://www.treccani.it/enciclopedia/ antonio-altan_\%28Dizionario_Biografico\%29/) 
sanjuanista ${ }^{18}$. Su estirpe, asimismo, vinculada a la de Ezpeleta y Garro (Labourd) y al servicio de la monarquía, se alineó en el bando agramontés durante el enfrentamiento y guerra entre el príncipe Carlos y su padre, proporcionándole a este último, recursos humanos y materiales de significativa importancia ${ }^{19}$.

Hasta el momento de la pugna por el cargo prioral, Sancho, que accedió a la categoría de caballero de la orden el 11 de septiembre de 1413 al tiempo que su hermanastro ${ }^{20}$, viajó a renglón seguido a la sede central de $\operatorname{Rodas}^{21}$, y fue nombrado comendador de Apat Hospital ${ }^{22}$, así como de Buñuel, Cabanillas y Fustiñana entre 1416 y 1426. Además recibió ese primer año y de manos de Galeote Monteti, visitador del maestre Filiberto de Naillac (1396-1421), el encargo de procurador general y receptor en el priorato de Navarra de las responsiones, rentas y demás derechos, cargo renovado por Antonio Fluviá (1421-1437) y su convento de Rodas en $1421^{23}$. Su ámbito de actuación también incluyó la rectoría del convento de freiras de Bargota, cerca de Mañeru y en el camino de Santiago ${ }^{24}$, y el ambicioso rediseño del cuadro comendaticio de la ribera y la merindad de Estella -lugar de concentración de poder de su familia-, al acceder

18 El merino Carlos y su hijo Felipe también ingresaron en la orden de San Juan. El primero sería acusado de apropiación indebida de Aberin y Echávarri (1454) y el segundo, recibido en la orden en 1459, tras la dispensa papal de Pio II por defecto de nacimiento (AHN, OO. MM., San Juan de Jerusalén, carp. 856, n. 99; CSJNa, n. 252); sería acusado también de apropiación indebida de Villafranca y Aberin (1477 y 1478), Patricia Burgui Fernández, El priorato navarro de la orden de San Juan de Jerusalén a finales de la Edad Media. Berenguer Sanz de Berrozpe 1478-1514, Pamplona, 2014, tesis de doctorado inédita, pp.154-158.

19 E. Ramírez Vaquero, Solidaridades nobiliarias, pp. 97-102 y 317-319.

20 La aprobación magistral para el nombramiento de Sancho como caballero consta en los registros magistrales con fecha del 27 de junio de 1413 (NLM, 338, 110r.). El verano de 1413, entre el mes de agosto y de septiembre, se registran en el reino de Navarra los pagos por parte del recibidor de las finanzas del rey Carlos III para costear el armamento y vestimentas que luciría Sancho de Echauz, y también su hermanastro Juan, chambelán del mencionado monarca, el día de ser nombrados caballeros de San Juan (septiembre, 11), y según la disposición del maestre de Rodas. La información conservada ratifica también dichos pagos mediante la orden real a los oidores de Comptos y al tesorero. Asimismo Sancho fue favorecido por el rey con un emolumento o gracia de 40 libras (José Ramón CASTRo, Catálogo de la Sección de Comptos: documentos, Institución Príncipe de Viana, Pamplona, 1962, vol. 30, n. 670, 671, 678, 697, 709, 875 y 896; y vol. 31, n. 366).

21 La documentación navarra de la Sección de Comptos no recoge la noticia del viaje a Rodas de Sancho, entre su nombramiento de caballero a finales del verano de $1413 \mathrm{y}$ su presencia en la comitiva que fue a recoger a la futura reina Blanca a Castilla en 1422 (J. R. CAstro, Catálogo de la Sección de Comptos: documentos, Institución Príncipe de Viana Pamplona, 1964, vol. 34, n. 391 y Georges Desdevises Du DeZERT, Don Carlos de Aragón, príncipe de Viana. Estudio sobre la España del norte en el siglo XV, p. 163). La licencia de salida de este freire se fecha en Rodas en octubre de 1413 (NLM, 338, 116r. y Ma BonET, "La centralización en el gobierno de priorato de Navarra”, pp. 237-238. Todo ello nos induce a pensar que viajó a Rodas poco después de ser nombrado caballero).

22 La provisión de las encomiendas se hizo el 5 de junio de 1416 (AHN, OO. MM., San Juan de Jerusalén, carp. 860, n. 26; CSJNa, n. 370 y NLM, 340, 106r.-106v.).

23 AHN, OO. MM., San Juan de Jerusalén, carp. 860, n. 25 (1416, abril 3), n. 28 (1421, noviembre 18); CSJNa, n.369 y 372, respectivamente. También Ma Bonet, "La centralización en el gobierno de priorato de Navarra", p. 192.

24 AHN, OO. MM., San Juan de Jerusalén, carp. 896, n. 117; CSJNa, n. 1543. 
a la titularidad de las sedes de Villafranca y Casanueva (1426, julio 1) ${ }^{25}$, Cogullo y Melgar (1426, septiembre 5) ${ }^{26}$, y especialmente Echávarri y Aberin (1428, enero 18) ${ }^{27}$. De la misma forma fue comendador de la cámara magistral de Pedriz $(1433)^{28}$. Sin embargo, esta brillante trayectoria, que quizá podría haber culminado con la dirección del priorato quedó truncada tras la desaparición de Martín Martínez de Olloqui, acaecida quizá entre el mes de octubre de 1433 y abril de $1435^{29}$, al entrar los Beaumont a pugnar por el cargo.

Se fecha en octubre de 1433 la noticia documental de los Libri bullarum en la que consta la incapacidad de Martín Martínez de Olloqui para gobernar por etate decrepita, depositando en Sancho de Echauz las funciones priorales. El registro figura tachado, lo que supone una extraña rectificación para la provisión del cargo, que es difícil identificar como una orden del maestre para castigar una posible falta disciplinaria del navarro. Esta anulación de lo que pudo ser una decisión inicial de Rodas proyectó probablemente los problemas existentes en Navarra causados por el control de la autoridad prioral, y más teniendo en cuenta que el anciano Olloqui vuelve a presidir un capítulo provincial año y medio después, en febrero de $1435^{30}$. ¿Qué estaba ocurriendo en el establecimiento hospitalario de Navarra? ¿Por qué se rectifica en el convento central la nominación de un prior que no llegó a alcanzar tal cargo? ¿Qué podía suponer la titularidad de un Echauz o un Beaumont?

\subsection{Las actividades priorales previas a la guerra civil (1433/35-1451)}

El conflicto entre Sancho de Echauz y Juan de Beaumont por obtener la dirección del Hospital en Navarra, fue uno más, por así decirlo, de los signos evidentes de la banderización política y nobiliaria de comienzos del siglo XV. El matrimonio entre la heredera

25 El maestre de la orden elevó a Sancho al cargo de comendador de Villafranca y Casanueva, por la muerte del anterior, Juan de Ganuza (AHN, OO. MM., San Juan de Jerusalén, carp. 940, n. 44; C. CSJNa, n. 4580).

26 Cogullo y Melgar son actualmente dos despoblados en el valle de Santesteban de la Solana y la circunscripción de Los Arcos (Julia PAvón Benito, Poblamiento altomedieval navarro, Eunsa, Pamplona, 2001, pp. 254-255 y p. 305). El acceso a estas dos últimas encomiendas en la merindad de Estella, le supuso la renuncia a Cabanillas, Fustiñana y Buñuel (AHN, OO. MM., San Juan de Jerusalén, carp. 900, n. 7; CSJNa, n. 3206). El cambio en la titularidad de estas preceptorías podría situarse dentro del juego de intereses de los distintos linajes nobiliarios del reino, ya que en 1434 tomó posesión de las mismas, Miguel de Saut, por muerte de su antecesor, frey Beltrán de Echauz. En 1446, Juan de Beaumont accedió a ellas, al tiempo que desplazaba a Sancho de Echauz a la bailía de Tudela (M ${ }^{a}$ BonEt, "La centralización en el gobierno de priorato de Navarra", p. 193).

27 Echávarri y la antigua encomienda templaria de Aberin fueron unidas por el maestre para ceder su gobierno a Sancho (AHN, OO. MM., San Juan de Jerusalén, carp. 921, n. 77; CSJNa, n. 1120).

$28 \mathrm{M}^{\mathrm{a}}$ BONET, "La centralización en el gobierno de priorato de Navarra", p. 238.

29 Hasta el momento no está clara la fecha de la muerte del prior Martín Martínez de Olloqui que puede datarse entre el 12 de febrero de 1435 (AHN, OO. MM., San Juan de Jerusalén, caja 8516, 13/2; CSJNa, n. 1686) y el mes de abril de ese mismo año (AHN, OO. MM., San Juan de Jerusalén, carp. 888, n. 291; CSJNa, n. 2733).

30 NLM, 350, 159v.-160r. y Ma Bonet, "La centralización en el gobierno de priorato de Navarra”, p. 182, nota 6. Vid. nota 16. 
del reino de Navarra, Blanca, y el castellano Juan Trastámara, uno de los nobles del entorno monárquico mejor posicionados a nivel social y patrimonia ${ }^{31}$, abriría asimismo una nueva etapa en la política de este reino, y más a partir del fallecimiento del monarca Carlos III, en septiembre de 1425. Juan se convirtió en rey de este solar monárquico, si bien sus miras y actividades políticas se volcarían inicial y preferentemente sobre sus dominios e intereses diplomáticos castellanos ${ }^{32}$. El nuevo rey, que estuvo durante largas temporadas ausente de este dominio regio, ejerció durante su larga y prolija vida un gobierno según sus necesidades e intereses peninsulares ${ }^{33}$.

En 1429, tras su destierro de Castilla, el monarca solicitó la obtención de ayudas urgentes por un valor de 15.000 florines, ya que esa primavera comenzó una movilización fronteriza, que terminaría a comienzos del verano del año siguiente (Treguas de Majano) ${ }^{34}$. La negación inicial de ayuda económica de las cortes navarras en $1429^{35}$ acabaría saldándose con la venta de una parte de las joyas de la reina Blanca y otros objetos valiosos como imágenes religiosas, armas, libros y algunos ornamentos de uso litúrgico en Barcelona al comienzo de la disputa ${ }^{36}$. Asimismo consta la orden de recaudación de plata de las iglesias y de los deberes de asistencia económica de clérigos, legos y judíos $^{37}$. Las treguas de Majano supusieron una paz momentánea, pero, en palabras de José María Lacarra: el país había quedado muy dolido de la reciente contienda, y muy quebrantado por las recientes mortandades ${ }^{38}$.

La disputa no sólo tuvo sustanciales efectos económicos ${ }^{39}$, sino que los bordes suroccidentales del reino navarro fueron atacados y conquistados: Buradón, San

31 G. Desdevises du Dezert, Don Carlos de Aragón, príncipe de Viana, p. 151.

32 Jaume Vicens Vives, Juan II de Aragón (1398-1479), pp. 24-56, y G. Desdevises du Dezert, Don Carlos de Aragón, príncipe de Viana, pp. 167-168.

33 F. Idoate, Catálogo de la Sección de Comptos: documentos (Pamplona, 1968) vol. 48, n. 1039. Este documento de Leonor, hija de los reyes Juan y Blanca, y que se fecha tras la muerte del rey, certifica cómo éste consumió las riquezas de la reina en sus constantes conflictos peninsulares. El texto, por tanto, viene a ratificar esa imagen del rey como

34 J. Vicens Vives, Juan II de Aragón (1398-1479), pp. 56-65, y L. SuÁrez Fernández, "Los Trastámaras de Castilla y Aragón en el siglo XV (1407-1474)”, pp. 385-392.

35 Recoge la noticia José Yanguas, si bien no cita su fuente documental (José Yanguas y MiRAnda, Historia compendiada del reino de Navarra, Imprenta de Ignacio Ramón Baroja, San Sebastián, 1832, pp. 254-255).

36 José Ma Lacarra, Historia política del reino de Navarra desde sus orígenes hasta su incorporación a Castilla, Caja de Ahorros de Navarra, Pamplona, 1973, vol. 3, pp. 232-234. J. R. CAstro, Catálogo de la Sección de Comptos: documentos, Institución Príncipe de Viana, Pamplona, 1965, vol. 38, n. 81, 124, 126, y 151-157. Sobre el valor artístico de los objetos y su contexto cortesano puede consultarse Javier MARTíneZ DE AguiRre, "El honor de la corona. Los encargos artísticos de la reina Blanca de Navarra (1425-1441)", Goya, 334 (2011), pp. 38-39.

37 J. R. CAstro, Catálogo de la Sección de Comptos: documentos, Institución Príncipe de Viana Pamplona, 1965, vol. 38, n. 188, 190, 208 y vol. 50, n. 1128 (Pamplona, 1970, vol. 50).

38 J. Ma Lacarra, Historia política del reino de Navarra desde sus orígenes, vol. 3, p. 236.

39 Las cuantías económicas recaudadas y movidas durante la etapa que va de 1429 a 1436, tanto en el reino de Navarra como en el de Aragón son constatadas para Navarra por parte de J. Ma LACARRA, Historia política del reino de Navarra desde sus orígenes, vol. 3, p. 236 y para Aragón L. SuÁrez Fernández, "Los Trastámaras de Castilla y Aragón en el siglo XV (1407-1474)”, pp. 393-398. También aporta datos: E. 
Vicente de la Sonsierra, Cabredo, Genevilla y Laguardia. El control y defensa de franja territorial de la región de Estella había sido clave durante el conflicto, plaza de la que era merino Juan de Echauz, caballero sanjuanista y hermano de padre de quien en breve disputaría la dirección del priorato a Juan de Beaumont, Sancho de Echauz. De la misma forma Luis, hermano de Juan y condestable del reino, también tuvo un papel destacado en la frontera guipuzcoana durante este conflicto, movilizando distintos contingentes ${ }^{40}$.

Al margen de la intensa actividad diplomática que desplegaría el rey el lustro siguiente para recuperar su autoridad y una buena parte sus beneficios económicos perdidos desde su salida de Castilla en 1429, cabe pensarse en la alteración que esta nueva situación traería como consecuencia para Navarra. Juan incluso viajó a Italia, al encuentro de su hermano el rey de Aragón, Alfonso V, para buscar su apoyo en el más amplio sentido político del término, entre junio de 1434 y diciembre de 1435. A su vuelta a la Península Ibérica traería consigo la ratificación de la lugartenencia de Aragón y Valencia, aumentando formalmente su capacidad operativa a nivel diplomático ${ }^{41}$.

En este nuevo escenario político, y con la muerte del prior Martín Martínez de Olloqui (1433 o 1435) despuntará el linaje de los Beaumont, que ante los acontecimientos de los últimos años no podrá dejar pasar la ocasión de acceder al control de la institución sanjuanista, ocupando así un valioso espacio de autoridad y jurisdicción, tanto a nivel capilar en la tierras navarras, como transfronterizo e internacional. Juan de Beaumont se postuló como candidato para regir el priorato del Hospital, a pesar de que no cumplía las condiciones estatutarias para acceder a la dignidad prioral, al contrario que su rival, Sancho de Echauz, pues ni llevaba dos décadas en el cargo, ni había prestado servicios en Rodas ${ }^{42}$. A pesar de ello, recurrió al papado para acceder a un cargo, que según se ha visto, le podría permitir situarse no sólo como representante formal de la sede central de la orden, sino también como garante y valedor, a nivel regional, de una organización internacional y con especial peso en las complejas redes de la alta política tejidas en el Mediterráneo occidental.

El análisis de la documentación relativa al período de gobierno de Juan de Beaumont, poco más de media centuria, desprende las líneas maestras de actuación de lo que podría definirse como un caballero sanjuanista, más bien volcadas en atender "interesadamente" la gestión institucional. Los diplomas conservados relativos a la demarcación sanjuanista señalan una serie de cambios con respecto a etapas anteriores. Así, el primer texto en el que figura Juan al frente del Hospital, datado a mediados de

RAmírez VAquero, "Al rey lo que es del rey (1387-1496)", Estudios sobre la realeza navarra en el siglo $X V$, E. Ramírez Vaquero (dir.), Universidad Pública de Navarra, Pamplona, 2005, pp. 179-230.

40 E. Ramírez Vaquero, Solidaridades nobiliarias, p. 130.

41 J. Vicens Vives, Juan II de Aragón (1398-1479), pp. 73-79 y Alan Ryder, Alfonso the Magnanimous. King of Aragon, Naples and Sicily, 1396-1458, Clarendon Press, Oxford., 1990, pp. 199-227.

42 Los estatutos de 1344 determinaban que para acceder al cargo, un caballero tendría que superar los veinte años en la orden, siendo cinco de ellos presenciales en la demarcación a la que aspiraba gobernar (Helen Nicholson, The knights Hospitaller, Woodbridge, The Boydell Press., 2003, p. 72). 
abril de 1435, recoge lo que sería una de las bases de su programa: recuperar derechos, aunque para ello hubiera de litigar la provisión de los cargos eclesiásticos de Esquíroz y Cordovilla, dos localidades próximas a Cizur, y que habían sido cedidas a favor del rey $^{43}$. A renglón seguido y hasta el comienzo de la guerra en 1451, esta directriz se manifestó reordenando las titularidades y registrando detalladamente los ingresos de las encomiendas, especialmente en emplazamientos estratégicos como Cabanillas y Fustiñana $^{44}$, Leache ${ }^{45}$, o Cogullo y Melgar ${ }^{46}$, regidos por el círculo de caballeros de filiación agramontesa. Para ello, Juan llegó, incluso, a recurrir a la denuncia ante el maestre de Rodas, imputando a sus titulares de usurpación, como ocurrió en las dos últimas sedes mencionadas ${ }^{47}$.

El nombramiento magistral para Juan de Beaumont no llegó hasta el 19 de enero de $1441^{48}$, emitido por parte del maestre Jean de Lastic y su convento de Rodas, sede a la que viajó en torno a $1438^{49}$. Una vez formalizada su investidura eligió sus cámaras priorales, llevando a cabo una nueva articulación del mapa de la "reserva" del prior. Además de contar con la centenaria y próspera encomienda de Cizur, en la cuenca de Pamplona y que percibía rentas de más de sesenta localidades del entorno y valle adyacentes, seleccionó las sedes de Iracheta, en el camino de Santiago; Biurrun, situada en las laderas meridionales de la serranía del Perdón, y finalmente Ribaforada, sobre la fértil cinta del Ebro y próxima a la frontera aragonesa.

43 AHN, OO. MM., San Juan de Jerusalén, carp. 888, n. 291; CSJNa, n. 2733.

44 Miguel de Saut, dentro de las redes tejidas por el linaje de Juan de Beaumont, será nombrado el 28 de junio de 1444 receptor de las responsiones de las bailías de Cabanillas y Fustiñana, en sustitución de Lope Íñiguez de Ujué (AHN, OO. MM., San Juan de Jerusalén, carp. 898, n. 27; CSJNa, n. 1690). En la mencionada fecha, Miguel, ya es también comendador de Cogullo y Melgar (AHN, OO. MM., San Juan de Jerusalén, carp. 860, n. 38; CSJNa, n. 382).

45 Leache había sido una preceptoría regida por Gil de Sarasa (1419-1443), AHN, OO. MM., San Juan de Jerusalén, carp. 936, n. 26. Caja 8559 /2, n. 60 /3-4; carp. 869, n. 33; carp. 936, n. 27; carp. 936, n. 28; CSJNa, n. 3696, 607, 3697 y 3699, respectivamente.

46 El 6 de noviembre de 1434 frey Antonio Fluviá, maestre de la orden, confiere la encomienda de Cogullo y Melgar a frey Miguel de Saut, cercano al círculo beaumontés. por muerte de su antecesor, frey Beltrán de Echauz (AHN, OO. MM., San Juan de Jerusalén, carp. 900, n. 8; CSJNa, n. 3207). No obstante, en 1426 estas preceptorías estaban bajo la administración de Sancho de Echauz. Vid. nota 44.

$47 \mathrm{M}^{\mathrm{a}}$ BONET, "La centralización en el gobierno de priorato de Navarra", pp. 208-209.

48 NLM, 354, 171v.-172r. (Collatione Prioratus Navarre) y AHN, OO. MM., San Juan de Jerusalén, carp. 860 , n. 35; CSJNa, n. 379.

49 Se conserva el documento, de la Cámara de Comptos y fechado el 16 de Julio de 1438 mediante el cual la reina Blanca ordena el pago del viaje con cargo económico al hostal del príncipe de Viana (AHN, OO. MM., San Juan de Jerusalén, carp. 847, n. 3; CSJNa, n. 31). Un fragmento del texto lo publica Agustín Millares Carlo, Tratado de Paleografía española, Madrid, Espasa Calpe, 1983, vol. 3, n. 365. (1 ${ }^{\text {a }}$ ed. Madrid, Librería y Casa Editorial Hernando, 1932). Consuelo Gutiérrez del Arroyo interpreta erróneamente dicho texto, entendiendo que el príncipe de Viana viajó a Rodas (CSJNa, n. 31). Por otro lado, y al igual que en el caso de Sancho de Echauz, es difícil precisar en qué momento Juan de Beaumont se desplazó a Rodas, pero quizá fue entre el otoño de 1435 y de 1437, a tenor del análisis de la documentación prioral y real relativa a Navarra. 
MAPA

\section{Las titularidad de las encomiendas navarras (1416-1446)}

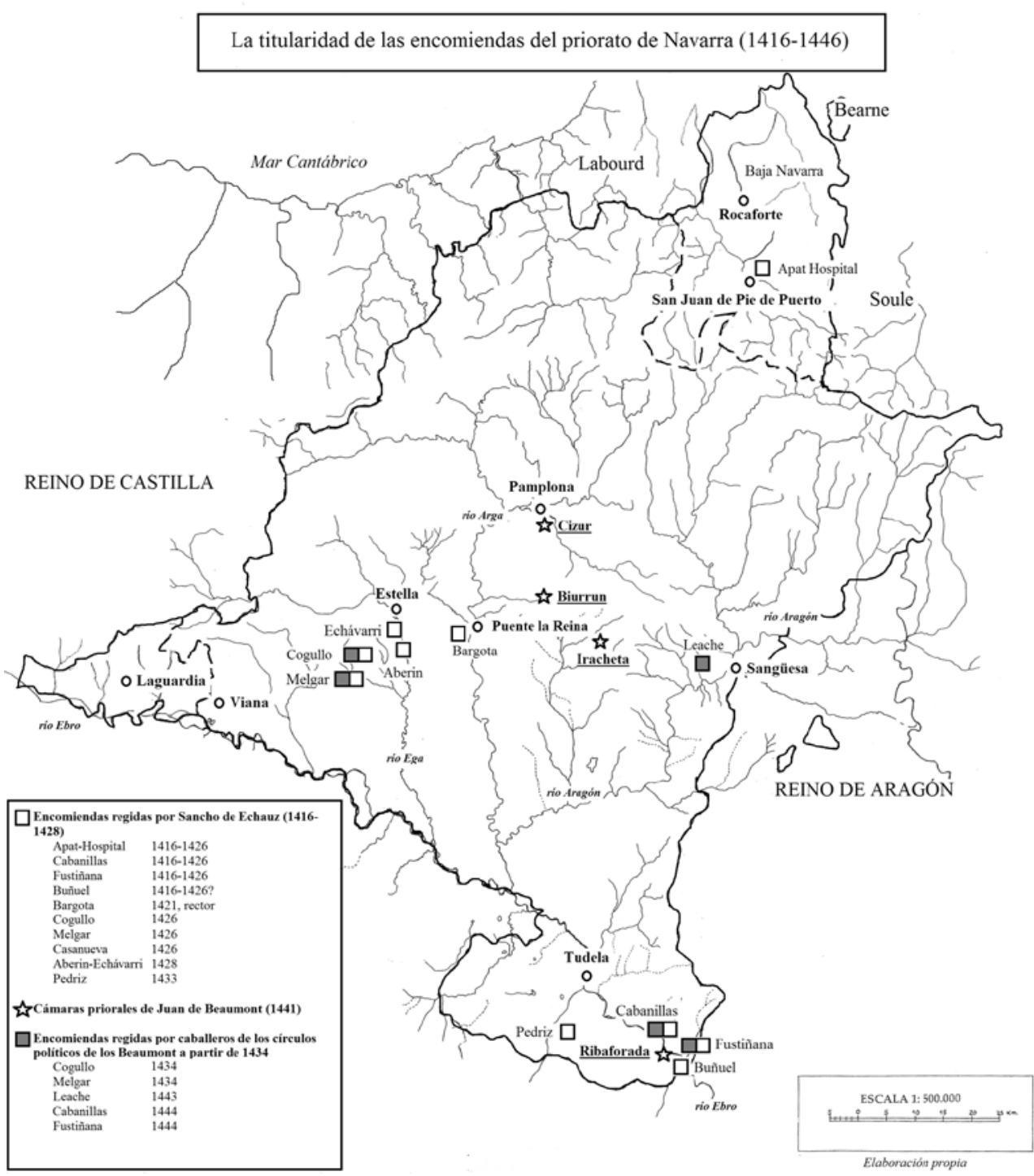

Este novedoso diseño de posesión de las cámaras priorales había sufrido, por tanto, un importante cambio con respecto a la etapa anterior de frey Martín Martínez de Olloqui, que disfrutó de Cizur, Calchetas, Bargota y Tudela $(1383)^{50}$. Desde luego que Cizur, en

$50 \quad \mathrm{M}^{\mathrm{a}}$ Bonet, "La centralización en el gobierno de priorato de Navarra", p. 221 y C. BARQuero, La orden de San Juan de Jerusalén en Navarra (siglos XIV-XV), p. 97 (C. Barquero transcribe Siuron en vez de Biuron, 
el camino jacobeo y a poca distancia de Pamplona en dirección meridional, centralizaba una de las más prósperas áreas de propiedades sanjuanistas en la cuenca pamplonesa. Precisamente, Juan procedió a reorganizar sus derechos, percepciones fiscales y demás posesiones dentro de su radio de influencia a partir de 1437, con el ánimo de rentabilizar y actualizar los ingresos de su más importante sede cercana a la capital. Para ello se hizo con el patronato, abadía, diezmos y primicias de Cordovilla, Esquíroz e Ipilce, este último hoy un despoblado ${ }^{51}$, y unos pocos años más tarde, iniciada la guerra civil (1454), nombró como "perteneciero" de la bailía de Cizur a García de Nagore para llevar a cabo el inventario de sus beneficios y dominios ${ }^{52}$. La confiscación de los bienes y rentas del prior y de su hermano Luis, el conde de Lerín, incluso antes de comenzar el conflicto y a lo largo de 1450, por parte del monarca Trastámara, fue decisiva a la hora de tomar la medida de proceder a contabilizar los activos de una preceptoría tan esencialmente dotada económicamente y emplazada estratégicamente ${ }^{53}$.

Biurrun, elevada al rango de encomienda el año 1383 por Juan Fernández de Heredia, era una casa dependiente de Cizur cercana al castillo de Tiebas, en la salida de la cuenca pamplonesa en dirección a Tafalla. El maestre, ese mismo año libró otras cuatro preceptorías (Ribaforada, Aberin, Fustiñana y Casanueva), más la cámara magistral de Calchetas, lo que supone una profunda renovación del cuadro y organización sanjuanista, una vez nombrado el nuevo prior Martín Martínez de Olloquir ${ }^{54}$. No obstante, con los datos obtenidos hasta la fecha no se adivinan las causas de la actuación magistral en aquella fecha con respecto a Biurrun, que más tarde tendría un papel significativo dentro de las estrategias diplomáticas de Juan de Beaumont, quizá por la cercanía de la fortificación de Tiebas, cuyas pechas formaron parte de sus fuentes de ingresos desde $1442^{55}$. La posición beaumontesa sobre la cuenca de Pamplona, con Cizur, se extendía hacia el mediodía con la cámara prioral de Biurrun, y también con Iracheta, centro que le permitió cerrar posiciones de protección sobre la cuenca, además de extender también su influencia y sacar rédito económico y político de la misma. Iracheta, en la Valdorba y cerca de Leache, presentaba los rasgos propios de un enclave con tradición centenaria en la ruta jacobea, y dentro de las redes más activas sanjuanistas ${ }^{56}$. Además, un año

el topónimo actual de Biurrun (AHN, OO. MM., San Juan de Jerusalén, carp. 860, n. 35; CSJNa, n. 379: 1441, enero 19: ... et cum preceptoriis de Cizur, Biuron, Iracheta et Ripeforate, cameris suis assignatis et conuentis quas...).

51 AHN, OO. MM., San Juan de Jerusalén, caja 8522/ 1, n. 9, CSJNa, n. 2734.

52 AHN, OO. MM., San Juan de Jerusalén, caja 8531/ 1. n. 27; CSJNa, n. 2740.

53 E. Ramírez Vaquero, Solidaridades nobiliarias, pp. 325-326.

$54 \quad M^{a}$ BONET, "La centralización en el gobierno de priorato de Navarra", pp. 191-192.

55 Una vez comenzado el conflicto, Tiebas será un reducto beaumontés vital en el intercambio de fuerzas entre el rey Juan y su hijo Carlos (E. Ramírez Vaquero, Solidaridades nobiliarias, pp. 133, 217, 228, 255, 277, y 327).

56 S. García Larragueta, El Gran Priorado de Navarra de la Orden de San Juan de Jerusalén, vol.1, pp. 165-166 (recoge la actividad de Iracheta en los siglos XII y XIII), y la documentación del AHN de Madrid indica la importancia de esta encomienda en el siglo XIV (AHN, OO. MM., San Juan de Jerusalén, carp. 936, n. 17; carp. 854, n. 63; carp. 884, n. 213; carp. 884, n. 212; CSJNa, n. 3687, 202, 2648 y 2647, respectivamente). 
después de convertirse Iracheta en cámara prioral, Juan en calidad de consejero real pasó a cobrar de los concejos del cercano valle pirenaico del Roncal $(1442)^{57}$.

Es posible considerar que Juan valorara controlar el área de la frontera con Aragón, pues inmediatamente después de hacerse con la cámara prioral de Iracheta y las rentas del Roncal, se detecta una actuación con el objeto de apropiarse de la bailía de Leache, por renuncia de Gil de Sarasa (1443), que consta al frente de la misma por lo menos desde $1419^{58}$. Curiosamente, sería Miguel de Saut, comendador de Cogullo y Melgar (1434), Cabanillas y Fustiñana (1444), un caballero próximo a su bando político, quien accedería a la titularidad administrativa de la misma ${ }^{59}$.

En última instancia, y situada sobre el espacio meridional del reino, se encontraba la antigua sede templaria de Ribaforada, dotada de importantes derechos eclesiásticos y explotaciones en un área no sólo fértil, sino estratégica, al mediodía de Tudela, Cabanillas y Fustiñana y a poca distancia de la frontera con Aragón. Todo este conjunto de circunstancias o parte de las mismas la sitúan en el punto de mira documental desde finales del siglo XI y todo el siglo XII, litigando con la colegiata de Tudela, cerrando acuerdos con el concejo de la villa por derechos de riego, afirmando el ejercicio del señorío de la orden sobre dicha localidad, y ajustando las concordias con su aljama de moros en relación a las condiciones de explotación de las tierras de la orden ${ }^{60}$. La encomienda, una vez incorporada al Hospital, también ajustó sus derechos, como el de la baja y mediana jurisdicción ${ }^{61}$, y afrontó las crisis del siglo XIV con una reforma de sus dominios y modelos de explotación de los mismos ${ }^{62}$. Por el contrario, tampoco puede olvidarse que la posición de Juan sobre esta preceptoría, en clave geográfica, le situaba sobre la ribera, núcleo de territorios agramonteses, facilitándole la comunicación con Aragón y también con Castilla ${ }^{63}$.

Mientras el prior sanjuanista procedía a esta nueva vertebración de influencias sobre el mapa navarro, en los primeros años de la década de los cuarenta, el rey proseguía sus enfrentamientos en Castilla. Las maniobras e intervenciones bélicas, proyectadas

\footnotetext{
57 E. Ramírez Vaquero, Solidaridades nobiliarias, p. 133.

58 Vid. nota 45.

59 Vid. nota 26, 44 y 46. Ma BONET, "La centralización en el gobierno de priorato de Navarra", p. 224, nota 101 , y p. 228 , nota 107. La autora refiere los registros de Malta donde se indica que Miguel era arrendatario de la preceptoría de Leache, entre otras.

60 Diplomatario de la orden del Temple en Navarra (en preparación).

${ }_{61}$ Se pueden citar las confirmaciones y sentencias favorables de los privilegios y la jurisdicción hechas por Carlos II el 5 de julio de 1351 (AHN, OO. MM., San Juan de Jerusalén, carp. 897, n. 19 y caja 8510, n. 12/2; carp.910, n. 25 y caja 8523, n. 20/1-3; CSJNa, n. 1676 y 4197). Otra sentencia favorable del mismo monarca sobre derechos y jurisdicción del 8 de marzo de 1381 (AHN, OO. MM., San Juan de Jerusalén, carp. 910, n. 27; CSJNa, n. 4200).

62 Entre finales del siglo XIV y comienzos del siglo XV, la preceptoría reajustó sus modelos económicos y las vinculaciones de explotación con los vecinos y concejos cercanos (AHN, OO. MM., San Juan de Jerusalén, carp. 869, n. 29; carp. 925, n. 40; carp. 887, n. 281; carp. 910, n. 28 y caja 8523, n. 28/2-6; AGN, Crucifijo, leg.18, n. 199; caja 8523, n. 29; caja 8516, n. 13/1; caja 8516, 13/2; caja 8523, n. 30; CSJNa, n. 603, 1927, 2719, 4201, 4202, 1686, 4203, respectivamente).

63 E. Ramírez Vaquero, Solidaridades nobiliarias, p. 60, 63, 101, 150-151, 162-163 y 165.
} 
y llevadas a cabo en cascada, condujeron nuevamente a una incómoda convocatoria y recaudación económica de los ingresos ordinarios y extraordinarios de Navarra con el objeto de financiar no sólo los conflictos fronterizos de su reino en la segunda parte del año 1444. Así, y hasta el estallido de la guerra civil, el Trastámara, que volvió a casarse en julio de 1447 con Juana Enríquez, recurrió en numerosas ocasiones a las Cortes para obtener apoyo pecuniario a sus empresas peninsulares ${ }^{64}$.

La actividad financiera también formó parte importante del desarrollo del priorato navarro, al generar una serie de rentas que no sólo revertían en beneficio propio, sino que se destinaban a los pagos anuales o responsiones dirigidos al tesoro central de Rodas. Las exigencias contributivas, incluso, se convertían en extraordinarias, si así se decidía en el convento central, a causa de necesidades defensivas por los conflictos en el Mediterráneo oriental ante el turco. Las características financieras de esta institución, le dotaron de singularidad, ya que además de generar un flujo pecuniario regular transfronterizo, creó unos mecanismos de gestión y control para su cumplimiento con flexibilidad y diversidad, pero también con las debidas garantías ${ }^{65}$.

En el conjunto de la orden, y tal y como ya adelantó M. Bonet, las aportaciones de Navarra apenas alcanzaban un pequeño porcentaje, según las escasas y dispersas noticias documentales que se han conservado. Si bien esta temática habrá de ser tratada monográficamente en otra ocasión, resulta de interés detenerse en algunos de los datos conservados, y sobre todo porque contamos con algunos elementos de comparación, al margen de los testimonios relativos al resto de las contribuciones priorales remitidas a la sede central en Rodas. El patrimonio regio navarro, objeto en los últimos años de un detallado análisis, podrá proporcionar el marco idóneo de fondo para evaluar la calidad y la cuantía de las rentas generadas dentro de los dominios sanjuanistas; si bien sería difícil llegar a grandes conclusiones pues las variables con respecto a la naturaleza, modelos y cargas impositivas son muchas, además de que habrían de establecerse otros puntos referenciales con respecto a los dominios eclesiásticos, y que ya han sido también estudiados ${ }^{66}$.

64 G. Desdevises du Dezert, Don Carlos de Aragón, príncipe de Viana, pp. 234-248, y José Ma Lacarra, Historia política del reino de Navarra desde sus orígenes hasta su incorporación a Castilla, vol. 3, pp. 253-261.

${ }_{65} \mathrm{M}^{\mathrm{a}}$ BONET, "La centralización en el gobierno de priorato de Navarra", p. 251.

66 E. Ramírez Vaquero viene analizando el patrimonio de la corona y la fiscalidad a lo largo de la segunda mitad del siglo XIV y XV: "Patrimonio de la corona e ingresos fiscales en Navarra en el siglo XV", Huarte de San Juan. Revista de la Facultad de Ciencias Humanas y Sociales, 2 (1995), pp. 73-98; "Hacienda y poder real en Navarra en la Baja Edad Media. Un esquema teórico", Príncipe de Viana, 60 (1999), pp. 87-118; "Valoración de la carga fiscal navarra en al siglo XV. Consideraciones y propuestas", Aragón en la Edad Media. Homenaje a la profesora Carmen Orcástegui Gros, 14-15-2 (1999), pp. 1283-1302; "Al rey lo que es del rey (1387-1496)", Estudios sobre la realeza navarra en el siglo XV, E. Ramírez Vaquero (dir.), Universidad Pública de Navarra, Pamplona, 2005, pp. 179-230. Peio Joseba Monteano Sobet se ha centrado en el estudio del patrimonio de la corona: Los navarros ante el hambre, la peste, la guerra y la fiscalidad: siglos XV y XVI, Universidad Pública de Navarra, Pamplona, 1999. Asimismo M. Berthe hizo un estudio de la evolución de las rentas de la tierra y del patrimonio regio entre la segunda mitad del siglo XIII hasta mediados del siglo XV: Famines et épidémies dans les campagnes navarraises à la fin du Moyen Age, SFIED, París, 1984, 2 vols. Los dominios eclesiásticos mejor estudiados en Navarra, y puntos de referencia, han sido los de San Sanlvador de Leire y santa María de Roncesvalles: Luis Javier ForTún, Leire, un señorío monástico (siglos IX-XIX), 
A modo de muestra, cabe citarse la aportación hecha por el priorato navarro en el año 1390, que ascendió a 500 florines, como parte de la solicitud global para todo el convento de 10.000 florines anuales para cuatro años. La castellanía de Amposta habría de ayudar con 2.000, y Castilla y Cataluña, con la mitad, 1.000 florines, respectivamente ${ }^{67}$. A finales del año 1440, Juan de Beaumont recibió por escrito el llamamiento del maestre Juan de Lastic para defender la isla ante los ataques de los mamelucos egipcios. La bula, conservada en el AHN, detalla la petición de combatientes, tanto de la orden como otros nobles, y de apoyo económico, si bien no se especifican cantidades ${ }^{68}$. Años más tarde, el maestre volvió a interpelar al priorato, con la misma finalidad, al igual que al resto de los territorios occidentales, tras la caída de Constantinopla $(1453)^{69}$.

La convocatoria a los capítulos generales también sirvió para atraer recursos humanos y pecuniarios $(1444,1445,1446,1450,1465,1477 \text { y 1486 })^{70}$. Los datos que estudia M. Bonet recogidos en los Libri Bullarum, ratifican dichas necesidades puntuales y las respuestas priorales ${ }^{71}$; al igual que los de las recaudaciones ordinarias realizadas, por ejemplo en 1378, 1453 como en 1474. Aunque las fechas de los recuentos no están circunscritas a esta primera etapa de gobierno de Juan de Beaumont, las cantidades dan una idea de la capacidad media económica de este priorato. Así, en 1387 el priorato navarro aportó 285 libras en su conjunto, lo que correspondería, según las equivalencias de J. Zabalo a unos 142,5 florines; en 1477 se constata el pago de 202 florines, 12 sueldos y 8 dineros, además de otros retrasos y aportaciones debidas al año siguiente, y en 1480 consta el pago de 5.107 sueldos en dineros jaqueses ${ }^{72}$.

Qué duda cabe que esta gestión retributiva incidió directamente sobre la articulación administrativa de cada una de las encomiendas, no sólo para reunir y satisfacer las responsiones, sino para actualizar, coordinar, y controlar el mapa impositivo de la orden a nivel capilar. El sistema financiero descansaba sobre la explotación de un patrimonio muy disperso y variado, y con fórmulas de gestión directa e indirecta que todavía está por estudiar, pero que a la luz de los inventarios bajomedievales conservados podría

Gobierno de Navarra, Pamplona, 1993; y Fermín Miranda García, Roncesvalles. Trayectoria patrimonial (siglos XII-XIX), Gobierno de Navarra, Pamplona, 1993.

$67 \mathrm{M}^{\mathrm{a}}$ BONET, "La centralización en el gobierno de priorato de Navarra", p. 253.

68 AHN, OO. MM., San Juan de Jerusalén, carp. 860, n. 34; CSJNa, n. 378.

69 Theresa M. VANN, "Rhodes and european Hospitaller priories", in International Mobility in the Military Orders (twelfth to fifteenth Centuries): Travelling on Christ's, Jochen Burgtorf and Helen Nicholson (eds.), University of Alabama, Tuscaloosa, 2006, pp. 40-41. Por ejemplo, consta que en 1453 las responsiones alcanzaron el monto de 50.000 florines (M $\mathrm{M}^{\mathrm{a}}$ BONET, "La centralización en el gobierno de priorato de Navarra", p. 256).

70 C. Barquero, "Repercusiones de la defensa de Rodas en los Hospitalarios navarros a fines de la Edad Media (siglos XIV-XV)", pp. 202-206.

71 Ma BONET, "La centralización en el gobierno de priorato de Navarra", p. 251 y 258-259.

72 Se han utilizado las tablas de equivalencia de Javier Zabalo Zabalegui, La administración del reino de Navarra en el siglo XIV, Eunsa, Pamplona, 1973, p. 238. Los datos de 1387 (AHN, OO. MM., San Juan de Jerusalén, carp. 869, n. 30), de 1477 (AHN, OO. MM., San Juan de Jerusalén, carp. 861, n. 53) y de 1480 (AHN, OO. MM., San Juan de Jerusalén, carp. 861, n. 58). También puede hacerse algún ejercicio comparativo en las tablas de la contabilidad relativas al patrimonio regio (1387-1496) aportadas por E. Ramírez VAQuero, Estudios sobre la realeza navarra en el siglo XV, pp. 204-230, 
conocerse con cierta precisión. Sería el caso de los libros o inventarios realizados entre los siglos XIV y XV para registrar las rentas del prior, y las de las encomiendas de Aberin, Bargota, Calchetas, Cizur Menor, Cogullo y Melgar, Tudela, así como Villafranca ${ }^{73}$. Su análisis, que se emplaza para otros trabajos en curso, quedará pendiente con el objeto de ir progresivamente presentando algunos resultados que ayuden a ampliar la actual secuencia de los conocimientos sobre esta materia.

Cabe considerar, en última instancia, que la respuesta prioral ante las llamadas y convocatorias de auxilio por parte de Rodas, no puede dejar en segundo plano que Juan pudo delegar la gestión más directa y activa del priorato en Pedro de Espinal, sobre todo a partir de 1453, ya que el de Beaumont se consagró a los asuntos políticos y de alta representación institucional, según deja notar la actividad documental referida a $\operatorname{ambos}^{74}$. Uno de los proyectos, por ejemplo, en el que sí volcó su personal esfuerzo el prior fue la fundación del convento del Crucifijo en Puente la Reina, apoyada por la casa real y el papado, a través de beneficios económicos y espirituales (1441 y 1447), obra que continuaría después del fin de la guerra ${ }^{75}$. La protección pontificia, muy celosa en tiempos de Eugenio IV (1431-1447) para con Navarra y orientada no sólo a la ratificación de beneficios, sino a la intervención en competencias propias de la institución sanjuanista como en la provisión de encomiendas (Leache), pudo ser reflejo de la ascendencia de una de las estirpes con mayor peso en el reino de Navarra ante el papado, necesitado, por otro lado de reafirmar su autoridad en los difíciles tiempos del conciliarismo ${ }^{76}$. De igual forma, no se puede olvidar que los ataques mamelucos y otomanos desde la segunda década del siglo XV renovaron el interés pontifical por apoyar a los Hospitalarios, ya desde los tiempos de Martín $\mathrm{V}^{77}$.

\footnotetext{
73 Consigna la relación de esta documentación C. BARQuero, La orden de San Juan de Jerusalén en Navarra (siglos XIV-XV), p. 179.

74 Pedro, por ejemplo, fue nombrado procurador general del tesoro por el maestre de Rodas en 1454 (AHN, OO. MM., San Juan de Jerusalén, carp. 860, n. 41; CSJNa, n. 385) y en 1472 (AHN, OO. MM., San Juan de Jerusalén, carp. 861, n. 50; CSJNa, n. 396) y administró una de las cámaras magistrales (AHN, OO. MM., San Juan de Jerusalén, carp. 925, n. 42; CSJNa, n. 1929). Los privilegios recibidos por este caballero conventual y los litigios que mantuvo por la provisión de preceptorías en Navarra desprenden, de un lado su cercanía al partido beaumontés, y de otro el control directo de la gestión prioral ( $\mathrm{M}^{\mathrm{a}}$ BONET, "La centralización en el gobierno de priorato de Navarra", p. 191-192, 196, 199, 203, 222, 231, 236-239, 248 y 259).

75 Luis Romera Iruela, "La fundación del monasterio del Crucifijo en Puente la Reina", Anuario de Estudios Medievales, 11 (1981), 597-632, y C. BARquero, La orden de San Juan de Jerusalén en Navarra (siglos $X I V-X V)$, pp. 128-132 y AHN, OO. MM., San Juan de Jerusalén, carp. 907, n. 8; CSJNa, n. 3971.

76 La temática sobre las relaciones con Eugenio IV requeriría una atención monográfica y comparativa. La vinculación del papa con Juan de Beaumont arranca del litigio habido con Sancho de Echauz y arbitrado por su auditor apostólico Antonio de San Vito (vid. nota 17), siguió con la intervención para la toma de posesión de la encomienda de Leache (AHN, OO. MM., San Juan de Jerusalén, carp. 936, n. 28; CSJNa, n. 3699) y con la protección a la política prioral de reordenar sus bienes y patrimonio (AHN, OO. MM., San Juan de Jerusalén, carp. 855, n. 88, 90 y 91; CSJNa, n. 233, 235, 236 y 164. Y AHN, OO. MM., San Juan de Jerusalén, carp. 857, n.128 y 131 y carp. 907, n. 8; CSJNa, n. 164 y 3971).

77 Theresa M. VANN, "Rhodes and european Hospitaller priories", pp. 38-39.
} 


\section{A modo de conclusión}

La muerte y desaparición del monarca Carlos III el Noble (1425) y de su hija y heredera, Blanca, en 1441, marcó en cierta forma el fin del proyecto político Evreux en Navarra. La llegada de un Trastámara a su corte (1425-1479), dio paso a un período novedoso, que catalizó las tendencias y trayectorias de un cambiante cuerpo social, según se advierte ya desde finales del siglo XIV. El nuevo escenario peninsular, especialmente convulso y conflictivo, protagonizado por la influencia de los infantes de Aragón, proporcionó, entre otras cosas, el fortalecimiento de unos clanes nobiliarios en detrimento de otros. Dentro de ese primer grupo, y en concreto en el reino navarro, se situó el linaje de los Beaumont, liderado por Luis, conde de Lerín, que con su prestigio pudo facilitar a su hermano Juan el ascenso a la dirección de una relevante institución, como la orden de San Juan. Para ello hubo de apartar al candidato más idóneo y preparado dentro del cuerpo de sus caballeros, Sancho de Echauz, saltarse la normativa estatutaria y lograr apoyos en el papado.

Como es de sobra conocido, la institución del Hospital en la Península Ibérica dio acogida en el siglo XV a nuevas y viejas oligarquías que buscaban crédito y reputación sociales, así como fuentes de ingresos que justificaran o expresaran su estatus económico. De manera que el formar parte o liderar alguna de las órdenes se convirtió en vehículo y reflejo individual y colectivo de influencias políticas; en definitiva, de pertenencia a los más pujantes círculos de poder.

La familia de Juan de Beaumont aprovechó la desaparición de Martín Martínez de Olloqui (c. 1435) para acceder al priorato navarro en un momento clave, a tenor de los que transmiten los contextos y las actividades políticas, tanto dentro de las fronteras del reino como en el resto de la Península Ibérica. El valor de una organización como la de San Juan de Jerusalén trascendió, para los miembros de este linaje, a su mera articulación regional. Prueba de ello es la intervención de la curia pontificia de Eugenio IV (1441) ante las reclamaciones del caballero Echauz, y que acabó beneficiando a Juan. Ello indica, que la ambición de los Beaumont por estar presentes al frente de esta institución, significaba ampliar sus círculos de relaciones, y más en territorios directa e indirectamente relacionados con la corona aragonesa, centro de los más activos movimientos diplomáticos de la Europa occidental y los asuntos mediterráneos.

En suma, la tupida red de vinculaciones y actividades políticas derivadas de la dirección del Hospital en Navarra fue lo suficientemente atractiva para que su máxima magistratura fuera un temprano objetivo de los Beaumont. Empero, un trabajo como este, focalizado sobre el espacio navarro durante tres lustros del gobierno de Juan, requerirá más adelante datos que permitan ampliar y/o aquilatar estos planteamientos con avales documentales y tras la lectura reposada de bibliografía que tenga marcos geográficos y cronológicos más amplios.

En su conjunto, igualmente, debe considerarse otra importante cuestión relativa al acceso a la orden de esta estirpe: la gestión patrimonial derivada del cargo, que les abrió 
la posibilidad de entrar en un espacio económico singular y ciertamente dinámico. El pago anual o periódico de las responsiones implicaba liquidez financiera, además de la intervención de distintos agentes locales y del convento central que garantizaban los desembolsos y entregas. Los mecanismos económicos, por lo tanto, tenían que ser eficaces, influyendo en cierta forma en los modelos y procesos de organización rentista y explotación patrimonial. Ello pudo suponer un atractivo añadido para esta familia, al frente de esta responsabilidad que indirectamente también les pudo generar beneficios, amén de cargas gravosas si se solicitaban ayudas extraordinarias por parte de Rodas ante el peligro musulmán.

La dimensión financiera del Hospital, junto con la organización de las encomiendas, a cuyo frente se nombraron caballeros del partido beaumontés, proporcionaron a Juan un control del sistema de garantías regionales de la orden, y en definitiva un peso suficiente como para hacer de esta institución un ámbito de actuación de sus intereses personales, políticos y por extenso de sus círculos nobiliarios. No obstante, esta mirada sobre las características en Navarra de la organización sanjuanista merecería también tener en cuenta, la otra cara de la moneda; esto es, su detallado desarrollo y organización en el plano institucional, ya que las directrices de su gobierno prioral también reflejaron los modelos e intencionalidades del gobierno central.

Juan de Beaumont, prior vitalicio hasta 1487, actuó liderando la orden entre dos complejas realidades: los conflictos peninsulares y el creciente dominio de los turcos otomanos del Mediterráneo oriental. Su figura y su obra, tanto en calidad de beaumontés como sanjuanista, presentan perfiles indisociables y fundamentales para entender y conocer su trayectoria, lo que supone que este trabajo es el comienzo del análisis de un dilatado itinerario.

Fecha de recepción: 22 de diciembre de 2014

Fecha de aceptación: 27 de febrero de 2015 